\title{
Exploring possibilities of enhancing water use efficiency in potato: A review
}

\author{
Rinki Khobra*1, Ashutosh Srivastava ${ }^{1}$, Pinky Raigond ${ }^{2}$, Alka Joshi ${ }^{2}$, Som Dutt ${ }^{2}$, Brajesh \\ Singh ${ }^{2}$ and Bir Pal Singh ${ }^{2}$ \\ ${ }^{1}$ ICAR-Indian Institute of Wheat and Barley Research, Karnal-132001 (Haryana), INDIA \\ ${ }^{2}$ ICAR-Central Potato Research Institute, Shimla-171001 (Himachal Pradesh), INDIA \\ *Corresponding author. E-mail: rinkikhobra@gmail.com
}

Received: May 9, 2016; Revised received: September 22, 2016; Accepted: April 25, 2017

Abstract: Climate change threatens the global agriculture sustainability. Among different kinds of abiotic stresses, water stress is the most devastating component which curtails potato crop productivity. Our recent knowledge is limited concerning water stress tolerance and water use efficiency in potato. Many efforts are being made by the scientific community to reduce water use and to produce "more crop per drop". This review elaborates quantitative and qualitative aspects of multiple stress mechanisms and their regulating system related to present scenario of water use efficiency (WUE) requirements. WUE can only be improved by using multidisciplinary promising research approaches like molecular breeding, high throughput genotyping, multi-gene transfer and bioinformatics applications to unleash the information needed to exploitation of required traits in potato.

Keywords: Genomics, Genotype, Proteomics, Stress, Water use efficiency

\section{INTRODUCTION}

Potato (Solanum tuberosum L.) is the most important non-cereal food crop worldwide (Pino et al., 2007). It is grown in more than 125 countries and consumed almost daily by more than a billion people. Being a versatile crop, potato is not only utilized as a food and feed crop but also as a raw material in many industries (Ortiz and Watanabe, 2004). Potato crop is vulnerable to numerous biotic and abiotic stresses but, because of its shallow root system, it is more prone to water stress (Jefferies, 1993) and insufficient moisture availability leads in reduction of quality and quantity as well (Devaux et al., 2010). Approximately $85 \%$ root length is concentrated in the upper layer $(0.3-0.4 \mathrm{~m})$ of the soil. Therefore, sufficient water availability is a critical issue for the targeted production of potato crop (Fabeiro et al., 2001). Global water usage has increased six-folds in the past 100 years and it is forecasted that the water requirement will get double before 2030, mainly because of irrigation practices (Wang et al., 2014). The water demand is increasing constantly for agriculture, but available water resources are decreasing due to continuous rise in world population, changing patterns of rainfall because of global climate change and evaporative demand in many cultivated areas. In the future, agriculture may not be a priority for water use, because of competition with other uses such as human consumption, urbanization, industrialization etc. So there will be a demand for new potato varieties with higher water use efficiency and drought resistance which require less irrigation as compared to the presently cultivated genotypes. To understand the mechanism of water use efficiency (WUE) in potato, trait specific study from morphophysiological to molecular level is the need of hour, so that the desired traits can be introgress in modern cultivars to enhance the productivity under water deficit conditions (Kaminski et al., 2015; WWAP, 2015).

Water use efficiency (WUE) can simply be defined as the ratio of outputs to input. Output includes increasing biomass / yield / energy content / saleable product / financial return etc. and inputs includes rainfall / irrigation / transpired water / evapotranspiration etc. But, in general WUE of a crop is the amount of dry matter produced per unit of water transpired. In the era, when water rather than land area is limiting, the required crops should produce a higher yield with the same water input, or the same yield with a lower water input. N. E. Borlaug (2000) said, how can we continue to expand food production for a growing world population within the parameters of limited water availability? The answer is that humankind will need to bring about a 'Blue Revolution -more crops for every drop' in the 21 st century to complement the Green revolution in the 20th century.

The pioneer research studies related to WUE were initiated by Briggs and Shantz in 1913. They first studied the water requirement of different species (corn, sorghum, millet, wheat, oat, barley, potato, alfalfa and soybean) for a whole growth period (Briggs and Shantz, 1914; Shantz and Piemeisel, 1927). They also explored difference in the water requirements between different varieties of the same crop, and suggested the 
possibility of developing plant varieties, which are still more efficient in water use. But, the focused research for potato under water deficit scenario was started in 60-80's by Burton (Burton 1966; Burton, 1981). Some species of potato like S. curtilobum Juz, S. curtilobum Bukasov and S. andigenum and Chaucha group of Solanum tuberosum were reported to have low drought susceptibility traits (Monneveux et al., 2013). After identification of key traits, the main target is to reduce the gap between yield potential and actual yield in drought prone environments. The basis of identification, selection and genesis of new variety should be based on the combined screening at different phenological levels. A direct link between stomatal function, transpiration and carbon assimilation was supported by many research groups (Willmer and Fricker, 1996; Farquhar et al., 2001; Hetherington and Woodward 2003; Lawson et al., 2011). Stomatal conductance is directly related to WUE and by manipulating the stomatal characteristics we can easily manipulate WUE (Rebetzke et al., 2002; Masle et al., 2005; Eisenach et al., 2012). Further studies conclude that partial closure of stomata tends to increase photosynthetic water use efficiency, which can be defined as a ratio of photosynthesis (A) to stomatal conductance $\left(g_{s}\right)$. Jones (1992), suggested that the optimal opening of stomatal aperture gives higher WUE without compromising at yield level. For controlling the stomatal aperture, guard cell membrane transporters are the important targets for genetic manipulation to improve crop performance under water limited regime. Besides these, several other traits which should be studied to come up with a plant type with higher WUE (Bita and Gerats, 2013). Improved WUE and a deep understanding of crop responses to water stress will help to reduce input requirements and lead to money saving for farmers (Saravia et al., 2016). This review paper explains the basis of WUE at physiological, biochemical and molecular levels for exploiting the natural genetic variation present within the species and also from the species other than potato, so as to get better yield even under water deficit conditions.

Physiological and biochemical responses under water stress: Due to the sessile life cycle, plants have evolved adaptive mechanisms to face adverse environmental variations during their life cycle. These adaptation includes numerous physiological and biochemical changes which generally vary with plant genotype and growth stages. Plant height, number of green leaves and leaf area are considered as most sensitive parameters to moderate drought conditions (Deblonde and Ledent, 2001). The depth of root penetration in the soil is directly related to water absorption as well water stress tolerance (Lahlou and Ledent, 2005). Tolerance of a plant under limited water regime has been associated with the control of growth, carbon transfer (Tourneux et al., 2003), osmotic adjustment (Heuer

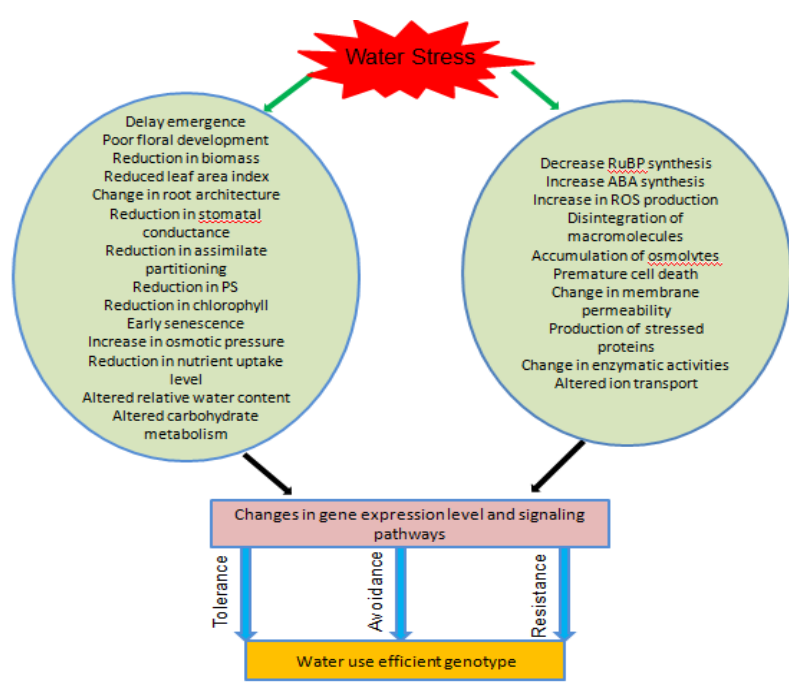

Fig. 1. Morphological, physiological, biochemical and molecular responses of a plant under water deficient condition.

and Nadler, 1998) and finally with enhanced water use efficiency (Alva et al., 2012). . Reduced water uptake also decreases nutrient absorption and transport to the roots by inducing root shrinkage and breakage of root soil contact (He and Dijkstra, 2014; Ahmad et al., 2013). So, WUE is a critical factor to determine the plant productivity under water deficit condition. Comparatively shallow spreading root architecture of potato is an undesirable trait under limited moisture availability conditions (Harris, 1992; Kleinkopf and Westermann, 1981; Bailey, 2000). Water scarcity not only imposes other abiotic stresses like drought and salinity but also limits the yield and quality of the produce. In potato, water stress during vegetative stage reduces plant height, leaf area, root development and this finally results in reduced/delay canopy development. Reduced root development causes a significant reduction in the number of tubers per plant which ultimately leads to decrease productivity. After the vegetative growth, the most critical stage for water deficiency is tuberization because water stress during tuberization will form pointed tuber ends, multiple knobs and other malformations. Water stress during tuber bulking stage increases the percentage of undersized tubers, decrease specific gravity and increase dark ends. Under water deficit condition, osmotic stress is the main factor which damages the structure of cell and cell organelles and disturbs the normal metabolic activities. Plant productivity under drought is closely associated with the osmotic adjustments made by the plant species such as Sorghum (Tangpremsri et al., 1995), Brassica sp. (Kumar and Singh, 1998) and Wheat (Morgan, 1984; El Hafid et al., 1998). At biochemical level, accumulation of reactive oxygen species (ROS) in plants, including superoxide radical $\left(\mathrm{O}^{-}\right)$and hydrogen peroxide $\left(\mathrm{H}_{2} \mathrm{O}_{2}\right)$ under water stress is a common adaptive phenomenon. Higher production of ROS can disrupt normal functioning and plant metabolic activities 


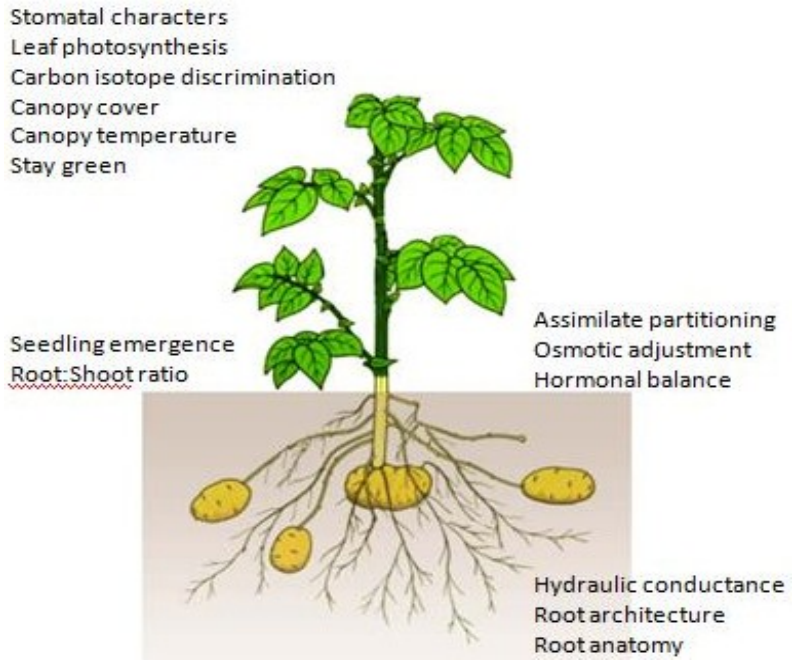

Fig. 2. Traits to be studied for water use efficiency.

through impaired enzyme activity due to oxidative damage, protein degradation, membrane lipid peroxidation and damage of DNA and RNA, which can ultimately culminate in cell death (Finkel and Holbrook, 2000). To limit ROS production, plants produce various types of antioxidants like superoxide dismutase (SOD), ascorbate peroxidase (APX), catalase (CAT), glutathione reductase (GR) and peroxidase (POX) etc. Proline acts as an non-enzymatic antioxidant to counteract the negative effects of numerous ROS and also as a signaling molecule in various metabolic activities which help plant to recover under sever stresses (Szabados and Savoure, 2010; Vankova et al., 2012). Besides, Proline, sugar alcohols, hexoses, pinitol, and metabolites like carotenoids, glutathione, ascorbic acid and $\alpha$-tocopherol have been found to be associated with water deficit tolerance in potato along with many other crops (Bansal and Nagrajan, 1986; Bohnert et al., 1995; Sairam et al., 2000). The higher production of antioxidant in response to oxidative stress induced by water stress is associated with the degree of stress tolerance of various plant species (Sunkar et al., 2006). Although, in case of potato it was reported by Wegener and Jansen (2013) that the level may increases, decreases or remains stable depending on the genotypic variability and type of antioxidant. Morphophysiological, biochemical and molecular responses of a plant under water deficient condition are illustrated in Fig 1.

Molecular responses under water stress: The most crucial line of defense under any kind of stress works at genetic level. The genes which are induced because of water stress can protect the plant by several means like, enhancing the production of osmoprotectants (proline, glycine betaine, sugars, polyamines), modifying metabolic proteins and regulating signal transduction pathway accordingly. Water stress induces a decrease in leaf water potential and stomatal conductance which will cause the down regulation of photosynthe- sis related genes. A gene mrp51 (Mitochondrial Ribosomal Protein), is associated with stomatal conductance and the transformed arabidopsis plants having mrp5-1, was found to have higher WUE (Klein et al., 2003; Ghasem et al., 2009). Glycinebetaine, a compatible solute, whose biosynthesis is catalyzed by choline oxidase (COD), acts as a scavenger for ROS and efficiently protects different components of photosynthetic machinery, like Rubisco (ribulose-1,5-bisphosphate carboxylas/oxygenase), photosystem II (PSII) from different types of stresses including the water stress. Cheng et al. (2013) studied the expression of choline oxidase (COD) under drought and found enhanced tolerance for water stress in transgenic potato plants bearing codA gene as compared to the non-transgenics. This COD gene was also introduced in many other plants like arabidopsis (Sulpice et al., 2003), tobacco (Huang et al., 2000), rice (Mohanty et al., 2002; Kathuria et al., 2009), tomato (Park et al., 2007; Goel et al., 2011; Li et al., 2011) and potato (Ahmad et al., 2008) to improve stress tolerance. Enhanced tolerance for drought and high temperature due to introduction of BADH (Betaine aldehyde dehydrogenase) gene in tomato (Jia et al., 2002), wheat (Guo et al., 2000) and potato (Zhang et al., 2009) has also been reported. The expression of Arabidopsis HARDY (HRD) gene in rice improves the water use efficiency by enhancing the assimilation of photosynthates and reducing transpiration. HRD over expression produces roots with enhanced strength, branching and thicker leaves with more chlorophyll bearing mesophyll cells which contribute towards enhanced WUE. HVA1, an ABA responsive barley gene was introduced into wheat and the transgenic showed higher WUE (Sivamani et al., 2000).

Root is the most susceptible part for water deficit in a tuber crop like potato, so modifications in root architecture can be an effective way to enhance the yield and production. Uga et al. (2013) demonstrated an increase in root growth angle by altering a rice quantitative trait locus (QTL), DEEPER ROOTING 1 (DRO1) through cloning and characterization. Higher expression of DRO1 increases the root growth angle so the roots grow in a more downward direction to reach up to the deeper soil layers for absorbing more water. Introducing DRO1 in a shallow root system like potato can be helpful in maintaining high water use efficiency under deficit irrigation. There are many transgenics with improved WUE in various crop plants. Various transcription factor (TF) related to abiotic stress have also been identified viz., MYB, MYC, DREB/CBF, ABF/AREB, WRKY (Wang et al., 2016). The transcription factor DREB1A transferred from Arabidopsis to peanut resulted in $40 \%$ higher transpiration efficiency (TE) than the untransformed control (BhatnagarMathur et al., 2007). In transgenic potato overexpression of DREB/CBF TFs has been reported to enhance 
drought tolerance (Iwaki et al., 2013).

Transcriptiomics and proteomics studies have identified the involvement of water stress tolerance related gene with various physiological processes. These studies resulted into the identification of various ABA biosynthesis related genes, chaperons, ROS related genes, iron homeostasis, late embryogenesis abundant (LEA). Some novel type of transcription factor like DST (drought and salt tolerance), a $\mathrm{C}_{2} \mathrm{H}_{4}$ type $\mathrm{TF}$, which control the expression of $\mathrm{H}_{2} \mathrm{O}_{2}$ homeostasis related genes and mediate stomatal closure were identified by Huang et al. (2009). In Solanum commersonii, (a wild potato variety) the over expression of C-repeat binding factors has been found to be associated with proline synthesis in potato (Pino et al., 2007, 2008). NFYA5, a drought-inducible nuclear TF has been reported in Arabidopsis which controls the stomatal aperture and hence proved to be linked with water stress tolerance (Li et al., 2008). The cap-binding protein 80 (CBP80), also known as Abscisic Acid Hypersensitive 1, (ABH1) gene in Arabidopsis thaliana is involved in the regulation of the ABA transduction pathway and in drought tolerance. SNAC1 (STRESS-REPONSIVE $\mathrm{NAC} 1$ ) is a rice guard cell related gene and its over expression enhanced ABA sensitivity and stomatal closure both under drought and salt stress in rice $(\mathrm{Hu}$ et al., 2006). MYB60, MYB61 TFs of Arabidopsis regulate stomatal aperture and water stress tolerance (Cominelli et al., 2005). AHK1, an Arabidopsis histidine kinase (AHK1) localized to the plasma mem- brane, functions as osmosensor. The over expression of AHK1 enhanced water stress tolerance in Arabidopsis. WUE is a multigenic trait, so transferring only a single gene, which is specific to a specific kind of stress, may not be sufficient to reach the required level of tolerance (Bohnert et al., 1995). The only approach is through multigene transfer, to enhance the WUE in potato (Chinnusamy et al., 2005).

Traits required for better selection of a water use efficient variety: Plants responses to water stress are not similar among different cultivars (Hassanpanah, 2010), as a function of stress occurrence period (Kashyap and Panda, 2003). There are many traits which are required for a better understanding of mechanisms underlying tolerance under water stress like gaseous exchange, fluorescence, carbon isotope discrimination, plant water status, root traits, canopy reflectance etc. Gas exchange occurs mainly through stomata and the stomatal conductance is mainly influenced by $\mathrm{CO}_{2}$ absorption and thus affects photosynthesis and other developmental process as well. ABA is the key regulator for stomatal conductance and more sensitive for water depletion. Endogenous ABA is produced rapidly during water stress so as to trigger a cascade of physiological responses. ABA mediated plant responses can be used for better selection. Recently, McAusland et al. (2013) combined thermal imaging and chlorophyll fluorescence technique to develop a screening method to measure alterations in intrinsic WUE. This approach is of duel significance

Table 1. Genes for drought tolerance tested in transgenic potato plants.

\begin{tabular}{|c|c|c|c|}
\hline Gene & Gene function & Abiotic stress tolerance & Reference \\
\hline StMYB1R-1 & $\begin{array}{l}\text { MYB-Like Domain Transcription Fac- } \\
\text { tor, activation of drought-related genes }\end{array}$ & $\begin{array}{l}\text { Reduced water loss and provide tolerance } \\
\text { under water deficit }\end{array}$ & Shin et al., 2011 \\
\hline DREB1B & Transcription factor & $\begin{array}{l}\text { Enhanced water stress tolerance } \\
\text { Enhanced freezing tolerance }\end{array}$ & $\begin{array}{l}\text { Movahedi et al., } \\
2012\end{array}$ \\
\hline TPS1 & Trehalose synthesis & Delayed wilting under water stress & Stiller et al.,2008 \\
\hline $\mathrm{SST} / \mathrm{FFT}$ & Fructan accumulation & $\begin{array}{l}\text { Reduced proline accumulation at low } \\
\text { water availability }\end{array}$ & Knipp et al.,2006 \\
\hline TaSTRG & Fructan accumulation & $\begin{array}{l}\text { Enhanced proline accumulation under } \\
\text { drought stress }\end{array}$ & Knipp et al.,2006 \\
\hline $\operatorname{cod} \mathrm{A}$ & Synthesize GB in chloroplast & $\begin{array}{l}\text { Enhanced salt tolerance } \\
\text { Enhanced drought tolerance }\end{array}$ & $\begin{array}{l}\text { Ahmad et al., } \\
2008\end{array}$ \\
\hline $\mathrm{BADH}$ & GN synthesis & Enhanced tolerance to drought and salinity & Zhang et al.,2011 \\
\hline StPPI1 & $\begin{array}{l}\text { Proton pump interactor from Sola- } \\
\text { numtuberosum involved in several } \\
\text { physiological processes }\end{array}$ & $\begin{array}{l}\text { Enhanced tolerance to water stress and } \\
\text { others abiotic stresses }\end{array}$ & $\begin{array}{l}\text { Garcia et al., } \\
2011\end{array}$ \\
\hline $\begin{array}{l}\text { Tomato } \mathrm{Cu}, \mathrm{Zn} \\
\text { superoxide } \\
\text { dismutases }\end{array}$ & Enhanced oxidative stress defense & Enhanced drought-osmotic tolerance & Perl et al., 1993 \\
\hline AtDHAR1 & $\begin{array}{l}\text { Membrane integrity, protecting chloro- } \\
\text { phyll against degradation, and } \\
\text { allowing faster removal of } \mathrm{H}_{2} \mathrm{O}_{\mathrm{s}}\end{array}$ & $\begin{array}{l}\text { Enhanced herbicide, water and salt } \\
\text { stress tolerance }\end{array}$ & $\begin{array}{l}\text { Eltayeb et al., } \\
2011\end{array}$ \\
\hline AtGR1 & Elevation GSH contents & $\begin{array}{l}\text { Enhanced tolerance to multiple environ- } \\
\text { mental stresses, including drought }\end{array}$ & $\begin{array}{l}\text { Eltayeb et al., } \\
2010\end{array}$ \\
\hline $\begin{array}{l}\text { Cytosolic gluta- } \\
\text { mine synthase }\end{array}$ & Reduced photorespiration & $\begin{array}{l}\text { Limiting } \mathrm{N} \text { loss due to photorespiration } \\
\text { under well-watered and well-fertilized } \\
\text { conditions }\end{array}$ & $\begin{array}{l}\text { Kaminski et al., } \\
2015\end{array}$ \\
\hline
\end{tabular}


because it provides both spatial and temporal images of stomatal conductance and carbon assimilation. Hence, we can access both, stomatal response and speed simultaneously with rates of photosynthesis, which would be suitable for identifying plants with faster stomata movement with no impairment in carbon assimilation. Another important parameter to identify a genotype for higher WUE is Carbon isotope discrimination (CID). It is the ratio of two stable $\mathrm{C}$ isotopes i.e. ${ }^{12} \mathrm{C}$ and ${ }^{13} \mathrm{C}$, which are negatively correlated with transpiration efficiency of any $\mathrm{C}_{3}$ species. CID also correlated well with water deficit conditions suggesting that it is a potential tool that can be used to identify a tolerant variety within the germplasm of any crop species. The variability in intrinsic photosynthetic capacity can be exploited for screening under water deficit conditions in potato (Minhas et al., 2003). Plant water status and its degree of osmotic adjustment with response to available soil water are critical to mark a variety as water stress tolerant. For selecting a genotype with higher WUE, it is important to evaluate it under well watered conditions along with the stressed one (Topbjerg et al.,2014). Small root length in the soil profile may be an important component of the potato plant's sensitivity to stress (Iwama and Yamaguchi, 2006). For a tuber crop like potato, root traits like deeper root system, high root dry weight and density are desirable. Deguchi et al. (2015) reported the correlation between hydraulic conductance in potato crop and its root system under water deficit conditions. It suggests that improved total root length enhances hydraulic conductance and increases leaf water potential. For maintaining higher yield under restricted irrigation, early vigorous root proliferation may be considered a useful selection trait, because it rapidly secures access to water available in deep soil layers (Puertolas et al., 2014).

Many workers proposed root pulling resistance as a quality parameter to quantify root development since a direct correlation was observed by Ekanayake et al. (1989) between tuber yield and root pulling resistance. Rolando et al. (2015) suggested leaf greenness as a water stress tolerant trait in potato as it indicates reduced chlorophyll degradation. When senescence is delayed, this stay green may reflect more photosynthetic activity along with re-mobilization of assimilates towards tubers. Figure 2 represents the traits to be studied for enhancing water use efficiency.

Partial root zone drying and water use efficiency: A new irrigation strategy termed as Partial Root-zone Drying (PRD) being investigated in many countries (Kang and Zhang, 2004). PRD is based on the assumption that by providing a partial water stress to the roots, we can control the stomatal opening which may reduce water loss substantially with a minimum loss of $\mathrm{CO}_{2}$ uptake (Jones, 1992). PRD involves irrigating only part of the root zone and leaving the other parts dry to a predetermined level before the next irrigation. PRD works on the principal of induction of the abscisic acid (ABA) based root to shoot chemical signaling system to regulate growth under water limited conditions. On the other side these alternative watering cycles also induce the growth of secondary roots, which decreases the pressure of drought stress (Loveys et al., 2001). So, this PRD thereby, increase WUE with a minimum cost of yield reduction (Davies et al., 2002). PRD has been shown to be successful in grapevines conserving up to $50 \%$ of water (Stoll et al., 2000; Loveys et al., 2001). The alternative cycle of drying and irrigation may stimulate the mineralization of organic $\mathrm{N}$, enhance aeration and moisture condition to complement microbial activities in the soil and are essential for the continuous signal networking from the root to shoot because a drought-primed root cannot sustain ABA production for a longer duration (Davies and Hartung, 2004). Shahnazari et al. (2008) observed stay green habit late in the season under PRD treatment in potato contributing towards high yield. In wheat and maize also an enhanced $\mathrm{N}$ uptake has been observed in PRD experiments (Kirda et al., 2005; Li et al., 2005; Li et al., 2007). An increase in the number of secondary root hairs was also reported under PRD (Liang et al., 1996, Mingo et al., 2004). Implementation of such kind of irrigation practices at field level enhances WUE.

Although there is a reduction in total yield but the yield obtained per unit of water used in irrigation increases, which make PRD a promising tool for water scars areas. The concept of lateral PRD (Liu et al., 2006) has now been replaced with vertical PRD (Puertolas et al.,2014) to understand the differential patterns of ABA accumulation under vertical and horizontal soil moisture gradients and it has been observed that horizontal partial root-zone drying (HPRD) might better trigger a long-distance ABA signal than vertical partial root-zone drying (VPRD) under conditions allowing simultaneous high (ABA) root and relatively high root water uptake (RWU) fraction (Puertolas et al.,2015). So, selection and use of PRD based cultivars in breeding programs can be a fruitful approach to develop water use efficient variety.

Present scenario: Multiple strategies have been proposed to enhance the potato productivity via increasing photosynthesis, controlling stomatal conductance and understanding gene expression (Obidiegwu et al., 2015). But the target of "more crop per drop" can only be achieved by increasing WUE. Potato yield is more likely to be source limited instead of sink during tuber bulking because water availability is a key production management factor and interaction between water and nitrogen influence potato yield mainly through affecting source capacity via the net photosynthetic rate, total leaf area and leaf life span ( $\mathrm{Li}$ et al., 2016).Recent biotechnological approaches provide 
new alternatives to improve WUE in crop plants including potato. The search for identification of genes responsible for high water stress tolerance in potato was started in 2007 with fructosyltransferase gene, increasing fructane accumulation under water deficit condition. Because of wide genetic variations present in the plant kingdom, there is a wide scope for exploring, exploiting and engineering WUE related genes. Several genes have been identified and transformed in potato to produce highly water use efficient plants (Table.1). Recent genome analysis research of plant water use efficiency is focused on the naturally occurring variation in the isotopic composition of plants. Measurements of component traits such as leaf nitrogen content, biomass allocation, and plant hydraulic conductance are now proved as reliable tools to understand the phenotypic mechanisms associated with quality trait loci (QTL) for WUE.

Another interesting approach for enhancing WUE is the introduction of crassulacean and metabolism into $\mathrm{C}_{3}$ plants. Water requirement for $\mathrm{CAM}$ is $20 \%$ of that required for $\mathrm{C}_{3}$ or $\mathrm{C}_{4}$ plants. Although there are several knowledge gaps to understand the temporal enzyme action and signaling pathway to control stomatal closing during day and opening at night (Tuberosa and salvi, 2006). Institute of Integrative Biology is working in collaboration with US scientists to develop a systems level view of the CAM pathway by developing a detailed understanding of the genes, proteins and metabolites involved in CAM. Comprehensive knowledge of the CAM 'parts-list' will permit forward engineering of CAM into $\mathrm{C} 3$ crops. To generate crop varieties with improved WUE, suited for better production under reduced water inputs, the key ratelimiting step in ABA synthesis is 9-cisepoxycarotenoid dioxygenase (NCED). Overexpression of NCED in plants using constitutive promoter causes increased $\mathrm{ABA}$ accumulation and a range of physiological changes including improved WUE. Tissue-specific over production of ABA, root-to-shoot signalling, the generation of random alterations in NCED expression and exploitation of natural allelic variation in ABA biosynthetic genes is the most extensively studied research area. Eight putative StYUC (Solanum tuberosum YUCCA) genes were identified and transgenic potato plants overexpressing AtYUC6 showed enhanced drought tolerance, reduced water loss and levels of reactive oxygen species in leaves. Hence, YUCCA pathway of auxin biosynthesis in potato may be exploited against abiotic environment stresses (Kim et al., 2013).

Recently, in a diploid backcross progeny (DMDD) of potato, a dense genetic and physical map has been constructed with a total of 2469 markers, including single nucleotide polymorphism (SNP), simple sequence repeats (SSRs) and diversity array technology (DArT) (Sharma et al., 2013). By using two parental genetic maps constructed using this already published genotypic data, and quantitative trait locus (QTL) analysis. Khan et al. (2015) identified 45 genomic regions associated with nine traits in well-watered and terminal drought treatments and 26 potentially associated with drought stress both in greenhouse and field trials. They also showed that in potato QTLs reflects multigenic control of traits related to water stress conditions. A QTL was identified on chromosome 1 containing three genes encoding isoforms of cytosolic glutamine synthase genes and these were identified for controlling the nitrogen loss due to phoptorespiration and hence contributing towards enhanced WUE and photosynthetic efficiency in potato (Kaminski et al., 2015). S. tuberosum has diverse wild relatives that can exchange genetic traits. These wild Solanum species have been used as donors for introgression of biotic and abiotic stress tolerance to S. tuberosum (Kikuchi et al., 2015).

\section{Conclusion}

WUE is a quantitative index of drought tolerance, drought resistance, drought avoidance and many other adaptive traits. Enhancement of a polygenic trait is interplay of the interaction of multiple interactive pathways. To develop water use efficient genotype identification and selection of a drought resistance genotype which uses water efficiently under to produce more biomass and better partitioning towards sink (tuber) is the prerequisite for future breeding programs. Wild species can act as donor for this purpose. There is a need to develop a reliable technology that can measure plant WUE efficiently by using quantifiable stress indicators. Adequate RWC for longer period, decrease in meristematic activity, increased root: shoot ratio are some key screening feature for a water use efficient genotype. In parallel, identification of key molecules involved in signaling mechanism, development of new biotechnological and bioinformatics tools may help us to dissect out the whole pathway. A lot of work has been done on potato but no theoretical ideotype or conceptual model has been proposed yet for potato. In future we believe that the genes directly controlling WUE, signaling under water deficit conditions and yield will be transferred to potato for improving productivity. High throughput genotyping linked with phenotypic methods like use of infrared thermo sensors, hyperspectral imaging, visible RBG imaging, chlorophyll fluorescence imaging (CFIM) can be utilized as a scalable screening base for WUE. Current scenario of below ground research adds an idea to study the interaction of root with soil microbes because microbes are notorious enough to reshape the root physiology. Multigene transfer should be the future strategy for limited irrigation agriculture. Dissecting the genetic architecture to identify QTLs, genome editing technology, mutagenesis and transgenic development are the new areas which should be ex- 
ploited for desirable modifications, so as to make a plant tolerant to environmental stresses including water stress.

\section{REFERENCES}

Ahmad, R., Kim, M., Back, K., Kim, H., Lee, H., Kwon, S., Murata, N., Chung, W. and Kwak, S. (2008). Stressinduced expression of choline oxidase in potato plant chloroplasts confers enhanced tolerance to oxidative, salt, and drought stresses. Plant Cell Reports, 27: 687698

Ahmad, R., Waraich, E. A., Ashraf, M. Y., Ahmad, S. and Aziz, T. (2013). Does nitrogen fertilization enhance drought tolerance in sunflower: A review. Journal of Plant Nutrition, 37: 942-963

Alva, A. K, Moore, A. D. and Collins, H. P. (2012). Impact of deficit irrigation on tuber yield and quality of potato cultivars. Journal of Crop Improvement, 26: 211-227

Bailey, R. J. (2000). Practical use of soil water measurement in potato production. In: Haverkort, AJ and MacKerron DKL, Management of nitrogen and water in potato production. Wageningen, The Netherlands: Wageningen Presss, Pp. 206-218

Bansal, K. C. and Nagarajan, S. (1986). Leaf water content, stomatal conductance and proline accumulation in leaves of Potato (Solanum tuberosum L) in response to water stress. Indian Journal of Plant Physiology, 29: 397-404

Bhatnagar-Mathur, P., Devi, M. J., Reddy, D. S., Lavanya, M., Vadez, V. and Sharma, K. K. (2007). Stressinducible expression of At DREB1A in transgenic peanut (Arachis hypogaea L.) increases transpiration efficiency under water-limiting conditions. Plant Cell Reports, 26: 2071-2082

Bita, C. E. and Gerats, T. (2013). Plant tolerance to high temperature in a changing environment: scientific fundamentals and production of heat stress-tolerant crops. Frontier in Plant Science, 4: 273

Bohnert, H. J., Nelson, D. E. and Jensenay R. G. (1995). Adaptations to environmental stresses. Plant Cell, 7: 1099-1111

Borlaug, N. E. (2000). The Green Revolution Revisited and the Road Ahead. Special $30^{\text {th }}$ Anniversary Lecture, Norwegian Nobel Institute, Oslo.

Briggs, L. J. and Shantz, H. J. (1913). The water requirements of plants. II. A review of the literature USA. Deartment Agriculture Bureau. Plant Industry Bulletin, 285: 1-96

Briggs, L. J. and Shantz, H. J. (1914). Relative water requirements of plants. Journal of Agricultural Research, $3: 1-$ 63

Burton, W. G. (1966). The Potato, a Survey of its History and of its factors influencing its yield, nutritive value, quality and storage. $2^{\text {nd }}$ Ed. H. Veeman \& Zonen N. V. Wageningen, Holland. Pp. 382

Burton, W. G. (1981). Challenges for stress physiology in potato. American Potato Journal, 58: 3-14

Cheng, Y. J., Deng, X. P., Kwak, S. S., Chen, W. and Eneji, A. E. (2013). Enhanced tolerance of transgenic potato plants expressing choline oxidase in chloroplasts against water stress. Botanical Studies, 54: 30

Chinnusamy, V., Jagendorf, A. and Zhu, J. K.
(2005). Understanding and improving salt tolerance in plants. Crop Science, 45: 437-448

Cominelli, E., Galbiati, M., Vavasseur, A., Conti, L., Sala, T. and Vuylsteke, M. (2005). A guard-cell-specific MYB transcription factor regulates stomatal movements and plant drought tolerance. Current Biology, 15:1196-1200

Davies, W. J. and Hartung, W. (2004). Has extrapolation from biochemistry to crop functioning worked to sustain plant production under water scarcity? In: Proceedings of the 4th International Crop Science Congress, Sep. 26-Oct. 1, 2004, Brisbane, Australia.

Davies, W. J., Wilkinson, S. and Loveys, B. R. (2002). Stomatal control by chemical signalling and the exploitation of this mechanism to increase water use efficiency in agriculture. New Phytologist, 153: 449-460

Deblonde, P. M. K. and Ledent, J. F. (2001). Effects of moderate drought conditions on green leaf number, stem height, leaf length and tuber yield of potato cultivars. European Journal of Agronomy, 14: 31-41

Deguchi, T., Iwama, K., Matsumoto, M. and, Tanigawa J. (2015). Effect of varietal difference in root system on hydraulic conductance in potatoes under different soil water conditions and planting dates. Potato Research, 58: $103-119$

Devaux A., Ordinola M. E., Hibon A. and Flores F. A. 2010. El sector papa en la región andina: Diagnóstico y elementos para una visión estratégica (Bolivia, Ecuador y Perú). In: (CIP), I. P. C. (Ed.).

Eisenach, C., Chen, Z. H., Grefen, C. and Blatt, M. R. (2012). The trafficking protein SYP121 of Arabidopsis connect programmed stomatal closure and $\mathrm{K}^{+}$channel activity with vegetative growth. The Plant Journal, 69: 241-251.

Ekanayake, I. J., De Datta, S. K. and Steponkus, P. L. (1989). Spikelet sterility and flowering response of rice to water stress at anthesis. Annals of Botany, 63: 257264

El Hafid, R., Smith, D. H., Karrou, M. and Samir, K. (1998). Physiological attributes associated with earlyseason drought resistance in spring durum wheat cultivars. Canadian Journal of Plant Science, 78: 227-237

Eltayeb, A., Yamamoto, S., Habora, M., Matsukubo, Y., Aono, M., Tsujimoto, H. and Tanaka, K. (2010). Greater protection against oxidative damages imposed by various environmental stresses in transgenic potato with higher level of reduced glutathione. Breeding Science, 60: 101-109

Eltayeb, A., Yamamoto, S., Habora, M., Yin, L., Tsujimoto, H. and Tanaka, K. (2011). Transgenic potato over expressing Arabidopsis cytosolic AtDHAR1 showed higher tolerance to herbicide, drought and salt stresses. Breeding Science, 61: 3-10

Fabeiro, C., Martín de Santa Olalla, F., de Juan, J. A. (2001). Yield and size of deficit irrigated potatoes. Agriculture Water Management, 48: 255-266

Farquhar, G. D., Caemmerer, S., Berry, J. A. (2001). Models of photosynthesis. Plant Physiology, 125: 42-45

Finkel, T. and Holbrook, N. J. (2000). Oxidants, oxidative stress and the biology of ageing. Nature, 408: 239-47

Garcia, M. N. M., Pais, S. M., TEllez-Inon, M. T. and Capiati, D. A. (2011). Characterization of StPPI1, a proton pump interactor from Solanum tuberosum L. that is upregulated during tuber development and by abiotic 
stress. Planta, 233: 661-674

Ghasem, H. S., Matthew, R., John, B. and Boyer, J. (2009). Conceptual framework for drought phenotyping during molecular breeding. Trend in Plant Science, 9: 488-496

Goel, D., Singh, A. K., Yadav, V., Babbar, S. B., Murata, N. and Bansal, K. C. (2011). Transformation of tomato with a bacterial codA gene enhances tolerance to salt and water stresses. Journal of Plant Physiology, 168: 1286-1294

Guo, B., Zhang, Y., Lee, H., Du, L., Lee, Y., Zhang, J., Chen, S. and Zhu, Z. (2000). The transformation and expression of wheat with Betaine aldehyde dehydrogenase (BADH) gene. Chinese Bulletin of Botany, 42: 279 283

Harris, P. M. (1992). The influence of genotype and water stress on the nitrogen requirement of the potato crop. Conference: Meeting of the Section Physiology of the EAPR. Le Conquet (France). 24-28 Jun 1991. Potato Research, 35(1): 72

Hassanpanah, D. (2010). Evaluation of potato cultivars for resistance against water deficit stress under in vivo conditions. Potato Research, 5: 383-392

He, M., and Dijkstra, F. A. (2014). Drought effect on plant nitrogen and phosphorous: a meta-analysis. New Phytologist, 204: 924-931

Hetherington, A. M. and Woodward, F. I. (2003). The role of stomata in sensing and driving environmental change. Nature, 424: 901-908

Heuer, B. and Nadler, A. (1998). Physiological response of potato plants to soil salinity and water deficit. Plant Science, 137: 43-51

Hu, H., Dai, M., Yao, J., Xiao, B., Li, X. and Zhang, Q. (2006). Overexpressing a NAM, ATAF, and CUC (NAC) transcription factor enhances drought resistance and salt tolerance in rice. Proceeding of National Academy of Sciences of U.S.A., 103: 12987-12992

Huang, J., Hirji, R., Adam, L., Rozwadowski, K., Hammerlindl, J., Keller, W. and Selvaraj, G. (2000). Genetic engineering of glycinebetaine production toward enhancing stress tolerance in plants: metabolic limitations. Plant Physiology, 122: 747-756

Huang, X. Y., Chao, D. Y., Gao, J. P., Zhu, M. Z., Shi, M., Lin, H. X. (2009). A previously unknown zinc finger protein, DST, regulates drought and salt tolerance in rice via stomatal aperture control. Genes \& Development, 23: 1805-1817

Iwaki T., Guo L., Ryals J. A., Yasuda S., Shimazaki T., Kikuchi A., Watanabe K. N., Kasuga M., YamaguchiShinozaki, K., Ogawa, T., Ohta, D. (2013). Metabolic profiling of transgenic potato tubers expressing Arabidopsis dehydration response element-binding protein 1A (DREB1A). Journal of Agriculture and Food Chemistry, 61: 893-900

Iwama, K. and Yamaguchi, J. (2006). Abiotic Stresses: In Handbook of potato production, improvement, and postharvest management, ed. J. Gopal and S. M. P Khurana, The Haworth Press.

Jefferies, R. A. (1993). Responses of potato genotypes to drought. I. Expansion of individual leaves and osmotic adjustment. Annals of Applied Biology, 122: 93-104

Jia, G., Zhu, Z., Chang, F. and Li, Y. (2002). Transformation of tomato with the BADH gene from Atriplex improves salt tolerance. Plant Cell Reports, 21: 141-146

Jones, H. G. (1992). Plants and microclimate: A quantitative approach to environmental plant physiology, 2nd ed., Cambridge University Press, Cambridge, U. K., Pp. 428 Kaminski, K. P., Korup, K., Andersen, M. N., Sonderkaer, M., Andersen, M. S., Kirk, H. G. and Nielsen, K. L. (2015). Cytosolic glutamine synthetase is important for photosynthetic efficiency and water use efficiency in potato as revealed by highthroughput sequencing QTL analysis. Theoretical and Applied Genetics, 128(11): 2143-2153

Kaminski, K. P., Kørup, K., Kristensen, K., Nielsen, K. L., Liu, F., Topbjerg, H. B., Kirk, H. G. and Andersen, M. N. (2015). Contrasting Water-Use Efficiency (WUE) responses of a potato mapping population and capability of modified ball-berry model to predict stomatal conductance and was measured at different environmental conditions. Journal of Agronomy and Crop Science, 201: 81-94

Kang, S. Z. and Zhang, J. H. (2004). Controlled alternate partial root-zone irrigation: its physiological consequences and impact on water use efficiency. Journal of Experimental Botany, 55: 2437-2446

Kashyap, P. S. and Panda, R. K. (2003). Effect of irrigation scheduling on potato crop parameters under water stressed conditions. Agriculture Water Management, 59: 49-66

Kathuria, H., Giri, J., Nataraja, K. N., Murata, N., Udaya, K. and Tyagi A. K. (2009). Glycinebetaine induced waterstress tolerance in codA-expressing transgenic indica rice is associated with up-regulation of several stress responsive genes. Plant Biotechnology Journal,7:512526

Khan, M. A., Saravia, D., Munive, S., Lozano, F., Farfan, E., Eyzaguirre, R. and Bonierbale, M. (2015). Multiple QTLs linked to agro-morphological and physiological traits related to drought tolerance in potato plant. Molecular Biology Reports, 33: 1286-1298

Kikuchi, A., Huynh, H. D., Endo, T. and Watanabe, K. (2015). Review of recent transgenic studies on abiotic stress tolerance and future molecular breeding in potato. Breeding Science, 65: 85-102

Kim J., Baek D., Park H., Chun H., Oh D., Lee M., Cha J., Kim W., Kim M. and Chung W. (2013). Overexpression of Arabidopsis YUCCA6 in potato results in high-auxin developmental phenotypes and enhanced resistance to water deficit. Molecular Plant, 6: 337-349

Kirda, C., Topcu, S., Kaman, H., Ulger, A. C., Yazici, A., Cetin, M. and Derici, M. R. (2005). Grain yield response and N-fertilizer recovery of maize under deficit irrigation. Field Crops Research, 93: 132-141

Klein, M., Perfus-Barbeoch, L., Frelet, A., Gaedeke, N., Reinhardt, D., Mueller-Roeber, B., Martinoia, E. and Forestier, C. (2003). The plant multidrug resistance $\mathrm{ABC}$ transporter AtMRP5 is involved in guard cell hormonal signaling and water use. The Plant Journal, 1: $119-129$

Kleinkopf, G. E. and Westermann, D.T. (1981). Predicting nitrogen requirements for optimum potato growth. Proc. Univ. Idaho Winter Commodity School, Pp. 81-84

Knipp, K. and Honermeier, B. (2006). Effect of water stress on proline accumulation of genetically modified potatoes (Solanum tuberosum L.) generating fructans. Journal of Plant Physiology, 163: 392-397

Kumar, A. and Singh, D. P. (1998). Use of physiological indices as a screening technique for drought tolerance in 
oilseed Brassica species. Annals of Botany, 81: 413420

Lahlou, O. and Ledent, J. F. (2005). Root mass and depth, stolons and roots formed on stolons in four cultivars of potato under water stress. European Journal of Agrono$m y, 22: 159-173$

Lawson, T., Caemmerer, S. and Baroli, I. (2011). Photosynthesis and stomatal behaviour. Progress in Botany, 72: 265-304

Li, W., Xiong, B., Wang, S., Deng, X., Yin, L., Li, H. (2016) Regulation Effects of Water and Nitrogen on the Source -Sink Relationship in Potato during the Tuber Bulking Stage. PLoS ONE 11(1): e0146877

Li, F., Liang, J., Kang, S. and, Zhang, J. (2007). Benefits of alternate partial root-zone irrigation on growth, water and nitrogen use efficiencies modified by fertilization by fertilization and soil water status in maize. Plant and soil, 295: 279-291

Li, S., Li, F., Wang, J., Zhang, W., Meng, Q., Chen, T. H., Murata, N. and Yang, X. (2011). Glycinebetaine enhances the tolerance of tomato plants to high temperature during germination of seeds and growth of seedlings. Plant, Cell \& Environment, 34: 1931-1943

Li, W. X., Oono, Y., Zhu, J., He, X. J., Wu, J. M., Iida, K. (2008). The Arabidopsis NFYA5 transcription factor is regulated transcriptionally and post transcriptionally to promote drought resistance. Plant Cell, 20: 2238-2251

Li, Z., Zhang, F. and, Kang, S. (2005). Impacts of the controlled roots divded alternative irrigation on water and nutrient use of winter wheat. Transactions of American Society of Agricultural Engineers, 21: 17-21

Liang, J., Zhang, J., Wong, M. H. (1996). Effect of air-filled soil porosity and aeration on the intial and growth of secondary roots of maize (Zea Maize). Plant and soil, 186: $245-254$

Liu, F. L., Shahnazari, A., Andersen, M. N., Jacobsen, S. E., Jensen, C. R. (2006). Physiological responses of potato (Solanum tuberosum L.) to partial root-zone drying: ABA signalling, leaf gas exchange, and water use efficiency. Journal of Experimental Botany, 57: 3727-3735

Loveys, B., Grant, J., Dry, P. and McCarthy, M. (2001). Progress in the development of partial root zone drying. CSIRO, Plant Industry, University of Adelaide, SARDI.

Masle, J., Gilmore, S. R. and Farquhar, G. D. (2005). The ERECTA gene regulates plant transpiration efficiency in Arabidopsis. Nature, 436: 866-870

McAusland, L., Davey, P. A., Kanwal, N., Baker, N. R. and Lawson, L. (2013). A novel system for spatial and temporal imaging of intrinsic plant water use efficiency. Journal of Experimental Botany, 64: 4993-5007

Mingo, D. M., Theobald, J. C., Bacon, M. A., Davies, W. J. and, Dodd, I. C. (2004). Biomass allocation in tomato (Lycopersicon esculentum) plant's grown under partial root zone drying: enhancement of root growth. Functional Plant Biology, 31: 971-978

Minhas, J. S., Khurana, S. M. P., Sheshshayee, M. S. and Udayakumar, M. (2003). Potato varieties show genetic variability in water use efficiency based on carbon isotope discrimination. Journal of Indian Potato Association, 30: 193-194

Mohanty, A., Kathuria, H., Ferjani, A., Sakamoto, A., Mohanty, P., Murata, N. and Tyagi, A. (2002). Transgenics of an elite indica rice variety Pusa Basmati 1 harbouring the codA gene are highly tolerant to salt stress. Theoret- ical and Applied Genetics, 106: 51-57

Monneveuxa, P., Ramirez, D. A. and Pino, M. T. (2013). Drought tolerance in potato $(S$. tuberosum L.) Can we learn from drought tolerance research in cereals? Plant Science, 206: 76-86

Morgan, J. M. (1984). Osmoregulation and water stress in higher plants. Annual Review of Plant Physiology, 35: 299-319

Movahedi, S., Tabatabaei, B., Alizade, H., Ghobadi, C., Yamchi, A. and Khaksar, G. (2012). Constitutive expression of Arabidopsis DREB1B in transgenic potato enhances drought and freezing tolerance. Biologia Plantarum, 56: 37-42

Obidiegwu, J. E., Bryan, G. J., Jones, H. G. and Prashar, A. (2015). Coping with drought: stress and adaptive responses in potato and perspectives for improvement. Frontier of Plant Science, 6: 542

Ortiz R. and Watanabe K. N. (2004) Genetic contributions to breeding polyploid crops. Recent Research Development in Genetics \& Breeding, 1: 269-286

Park, E., Jekni, Z., Pino, M., Murata, N., Chen, T. (2007). Glycinebetaine accumulation is more effective in chloroplasts than in the cytosol for protecting transgenic tomato plants against abiotic stress. Plant Cell \& Environment, 30: 994-1005

Perl, A., Perl-Treves, R., Galili, S., Aviv, D., Shalgi, E., Malkin, S. and Galun, E. (1993). Enhanced oxidative stress defense in transgenic potato expressing tomato $\mathrm{Cu}, \mathrm{Zn}$ superoxide dismutases. Theoretical and Applied Genetics, 85: 568-576

Pino, M. T., Skinner, J. S., Jeknic, Z., Hayes, P. M., Soeldner, A. H., Thomashow, M. F. and Chen, T. H. H. (2008). Ectopic AtCBF1 over-expression enhances freezing tolerance and induces cold acclimationassociated physiological modifications in potato. Plant Cell \& Environment, 31: 393-406

Pino, M. T., Skinner, J. S., Park, E. J., Jeknic, Z., Hayes, P. M., Thomashow, M. F. and Chen, T. H. H. (2007). Use of a stress inducible promoter to drive ectopic AtCBF expression improves potato freezing tolerance while minimizing negative effects on tuber yield. Plant Biotechnology, 5: 591-604

Puertolas, J., Ballester, C., Elphinstone, D. and Dodd, I. C.. (2014). Two potato (Solanum tuberosum) varieties differ in drought tolerance due to differences in root growth at depth. Functional Plant Biology, 41: 11071118

Puertolas, J., Conesa, M. R., Ballester, C., \& Dodd, I. C. (2015). Local root abscisic acid (ABA) accumulation depends on the spatial distribution of soil moisture in potato: implications for $\mathrm{ABA}$ signalling under heterogeneous soil drying. Journal of Experimental Botany, 66 (8): $2325-2334$

Rebetzke, G. J., Condon, A. G., Richards, R. A., Farquhar and G. D. (2002). Selection for reduced carbon isotope discrimination increases aerial biomass and grain yield of rainfed bread wheat. Crop Science, 42: 739-745

Rolando, J. L., Ramirez, D. A., Yactayo, W., Monneveux, P. and Quiroz, R. (2015). Leaf greenness as a drought tolerance related trait in potato (Solanum tuberosum L.). Environmental and Experimental Botany, 110: 27-35

Sairam, R. K., Srivastava, G. C. and Saxena, D. C. (2000). Increased antioxidant activity under elevated temperature: a mechanism of heat stress tolerance in wheat 
genotypes. Biologia Plantarum, 43: 245-251

Saravia, D., Farfán-Vignolo, E. R., Gutiérrez, R. et al. Yield and physiological response of potatoes indicate different strategies to cope with drought stress and nitrogen fertilization. American Journal of Potato Research, (2016) 93: 288

Shahnazari, A., Ahmadi, S. H., Laerke, P. E., Liu, F., Plauborg, F., Jacobsen, S. E., Jensen, C. R. and, Andersen, M. N. (2008). Nitrogen dynamics in the soil-plant system under deficit and partial root-zone drying irrigation strategies in potatoes. European Journal of Agronomy, 28: 65-83

Shantz, H. J. and Piemeisel, L. N. (1927). The water requirement of plants at Akron, Colorado Journal of Agricultural Research, 34: 1093-1190

Sharma, S. K., Bolser, D., de Boer, J., Sonderkaer, M., Amoros, W., Carboni, M. F., Bryan, G. J. (2013). Construction of reference chromosome-scale pseudomolecules for potato: integrating the potato genome with genetic and physical maps. G3 Genes Genomes Genet, 3: 2031 $-2047$

Shin, D., Moon, S. J., Han, S., Kim, B. G., Park, S. R., Lee, S. K., Yoon, H. J., Lee, H. E., Kwon, H. B., Baek, D., Yi, B. Y. and Byun, M. O. (2011). Expression of StMYB1R-1, a novel potato single MYB-like domain transcription factor increases drought tolerance. Plant Physiology, 155: 421-432

Sivamani, E., Bahieldinl, A., Wraith, J. M, Niem, T. A., Dyer, W. E., David, T. H. and Qu, R. D. (2000). Improved biomass productivity and water use efficiency under water deficit conditions in transgenic wheat constitutively expressing the barely HVA1 gene. Plant Science, 155: 1-9

Stiller, I., Dulai, S., Kondrak, M., Tarnai, R., Szabo, L.L., Toldi, O. and Banfalvi, Z. (2008). Effects of drought on water content and photosynthetic parameters in potato plants expressing the trehalose-6-phosphate synthase gene of Saccharomyces Cerevisiae. Planta, 227: 299-308

Stoll, M., Loveys, B. and Dry, P. (2000). Hormonal changes induced by partial root zone drying of irrigated grapevine. Journal of Experimental Botany, 51: 1627-1634

Sulpice, R., Tsukaya, H., Nonaka, H., Mustardy, L., Chen, T. and Murata, N. (2003). Enhanced formation of flowers in salt stressed Arabidopsis after genetic engineering of the synthesis of glycine betaine. The Plant Journal, 36: 165-176

Sunkar, R., Kapoor, A. and Zhu, J. K. (2006). Post transcriptional induction of two $\mathrm{Cu} / \mathrm{Zn}$ superoxide dismutase genes in Arabidopsis is mediated by down regulation of miR398 and important for oxidative stress tolerance. Plant Cell, 18: 2051-2065

Szabados, L., and Savoure, A. (2010). Proline: a multifunctional amino acid. Trends in Plant Science, 15, 89-97

Tangpremsri, T., Fukai, S. and Fischer, K. S. (1995). Growth and yield of sorghum lines extracted from a population for differences in osmotic adjustment. Australien Journal of Agriculture Research, 46: 61-74

Topbjerg H. B., Kaminski, K. P., Markussen, B., Kørup, K., Nielsen, K. L., Kirk, H. G., Andersen, M. N., Liu, F. (2014). Physiological factors affecting intrinsic water use efficiency of potato clones within a dihaploid mapping population under well-watered and droughtstressed conditions, Scientia Horticulture, 178: 61-69

Tourneux, C., Devaux, A., Camacho, M. R., Mamani, P. and Ledent, J. F. (2003). Effects of water shortage on six potato cultivars in the highlands of Bolivia (I): morphological parameters, growth and yield. Agronomie, 23: 169-179

Tuberosa, R. and Salvi, S. (2006). Genomics approaches to improve drought tolerance in crops. Trends in Plant Science, 11: 405-412

Uga, Y., Sugimoto, K., Ogawa, S., Rane, J., Ishitani, M. and Hara, N. (2013). Control of root system architecture by DEEPER ROOTING1 increases rice yield under drought conditions. Nature Genetics, 45: 1097-1102

Vankova, R., Dobra, J., and Storchova, H. (2012). Recovery from drought stress in tobacco: an active process associated with the reversal of senescence in some plant parts and the sacrifice of others. Plant Signaling \& Behavior, 7: 19-21

Wang, H., Wang, H., Shao, H., \& Tang, X. (2016). Recent Advances in Utilizing Transcription Factors to Improve Plant Abiotic Stress Tolerance by Transgenic Technology. Frontiers in Plant Science, 7: 67

Wang, Y., Hills, A. and Blatt, M. R. (2014). Systems analysis of guard cell membrane transport for enhanced stomatal dynamics and water use efficiency. Plant Physiology, 164: 1593-1599

Wegener, C. B. and Jansen, G. (2013). Antioxidants in different potato genotypes: effect of drought and wounding stress. Agriculture, 3: 131-146

Willmer, C. and Fricker, M. (1996). Stomata. 2nd edn. London: Chapman and Hall. New York, 231-278

WWAP (United Nations World Water Assessment Programme). (2015). The United Nations World Water Development Report 2015: Water for a Sustainable World. Paris, UNESCO.

Zhang Z, Shao, H., Xu, P., Hu, M., Song, W. and Hu, X. (2009). Full Length Research Paper Focus on agricultural biotechnology: Prospective for bio-water saving theories and their applications in the semi-arid and arid areas. African Journal of Biotechnology 8(12): 27792789

Zhang, N., Ci, H., Li, L., Yang, T., Zhang, C. and Wang, D. (2009). Enhanced drought tolerance of potato with introduced BADH gene. Acta Agronomica Sinca, 35: 11461150

Zhang, N., Si, H., Wen, G., Du, H., Liu, B. and Wang, D. (2011). Enhanced drought and salinity tolerance in transgenic potato plants with a $B A D H$ gene from spinach. Plant Biotechnology Reports, 5: 71-77 